DOI: 10.17805/zpu.2015.3.6

\title{
Украинское общество: кризис доверия в условиях неопределенности *
}

\author{
В. И. ЧУПРОВ
}

(ИНСТИТУТ СОЦИАЛЬНО-ПОЛИТИЧЕСКИХ ИССЛЕДОВАНИЙ РАН), B. В. МИХEEBA

(МОСКОВСКИЙ ГОСУДАРСТВЕННЫЙ ГУМАНИТАРНО-ЭКОНОМИЧЕСКИЙ УНИВЕРСИТЕТ)

В статье рассматривается проблема неопределенности в социальных взаимодействиях, различные формы проявления неопределенности в трансформирующемся обществе Украины. Обращается внимание на неструктурированность украинского общества, создание нового типа социальной реальности, ее негативный характер, разновидности доверия, уровень доверия и недоверия личностям и организациям.

В статье использованы результаты социологического исследования, проведенного в 26 областях Украины в 2012 г. Институтом социологии Академии наук Украины под руководством академика В. М. Вороны (выборка 1800 чел.). Данные исследований позволяют

* Подготовлено при поддержке РГНФ (проект «Аоверие как фактор саморегуляции в изменяющейся социальной реальности», грант № 14-03-00484).

The article was prepared with support from the Russian Foundation for the Humanities (Project title "Trust as a Factor of Self-regulation in the Changing Social Reality", grant No. 14-03-00484). 
отмечать негативную тенденцию изменения всех без исключения характеристик социальной реальности. В сознании большинства респондентов доминирует представление об украинском обществе как быстро меняющемся, неустойчивом, беспорядочном. Уровень доверия в украинском обществе определяется степенью близости (родственной, деловой и духовной) в социальных взаимодействиях при снижении уровня доверия ко всем политическим институтам и правоохранительным органам.

Делается вывод о том, что Украина демонстрирует многообразие форм проявления неопределенности в трансформирующемся обществе, а уровень доверия в украинском обществе является самым низким в Европе. Это свидетельствует о влиянии не только общих факторов (глобализации, кризиса, уровня экономического развития, политической стабильности), но и специфических условий историко-культурного развития страны, поскольку в целом снижение доверия - общая тенденция для европейских обществ.

Ключевые слова: Украина, украинское общество, украинский кризис, социальные взаимодействия, доверие, недоверие, социальная неопределенность, Европейское социальное исследование.

\section{ВВЕАЕНИЕ}

$\Pi$ оследние два десятилетия стали для украинского общества временем преобразований и активных трансформаций. Начиная с 90-х годов XX в. развитие украинского общества характеризуется перманентными кризисами во многих сферах общественной жизни и как следствие - изменением различных аспектов существования индивида в кризисном обществе, трансформацией поля для реализации возможностей человека. Изменение среды, т. е. экономических, политических и других предпосылок, привело к изменениям типа воспитания, а следовательно - культуры, а также к изменению образования, а значит - знания. Меняются самосознание, самоопределение, самоидентичность, целенаправленность. Усложнение условий жизни в трансформирующемся обществе, распад традиционных ценностей, социальных связей, неспособность предложить социально значимый идеал личности с гуманным лицом и признанием общечеловеческих ценностей - все это заставляет испытывать общество и индивида состояние неуверенности, повышенных рисков, неопределенности.

\section{ОСНОВНЫЕ ФОРМЫ ПРОЯВАЕНИЯ НЕОПРЕАЕАЕННОСТИ В УКРАИНСКОМ ОБЩЕСТВЕ}

Социальная неопределенность вытекает из многообразия общественных связей, которые постоянно переживают этапы формирования и распада. Она возникает в связи с появлением новых структур, новых норм отношений, альтернатив во взаимодействиях и выступает необходимым источником выбора возможностей в социальных взаимодействиях. Если определенность в социальных взаимодействиях предполагает выбор из всего многообразия возможностей одной, но наиболее оптимальной в конкретных условиях, то в условиях неопределенности, характеризующейся исходя из принципа определенности В. Гейзенберга сочетанием двух (или нескольких) противоположных возможностей, выбор носит вероятностный характер. При этом вероятность зависит от масштаба проявления социальной неопределенности в трансформирующемся обществе, который может варьироваться от краткосрочных состояний кризиса до крайней неопределенности, выраженной в неструктурируемости, т. е. невозможности построения модели социального процесса, адекватной реальности. Исследуя социальную природу неопределенности и риска, Ю. А. Зубок выделяет две формы неструктурируемости: «...как принципиальную невозможность моделирования социальных процессов и как временное состояние неопределенности в конкрет- 
ной социальной ситуации, проявляющееся в несоответствии социальных изменений реально существующим структурам» (Зубок, 2007: 122).

В первой форме неструктурированность затрагивает фундаментальные основания общественных отношений, распространяясь на базовые характеристики социальной среды. Именно среда становится основным источником неопределенности в социальной системе. Ее базовые характеристики выступают условиями, которые воздействуют на все элементы социальной системы. Известно, что условия, рассматриваемые в сопоставлении с категориями причины и следствия тех или иных процессов в социальной системе, подразделяются на необходимые и достаточные. По мнению Е. Никитина, «если достаточные условия соблюдены, то объект возникает (существует, изменяется и т. А.) с необходимостью. Аостаточные условия обычно представляют собой некоторое множество объектов, причем каждый элемент этого множества, а также каждое из входящих в него подмножеств является необходимым условием, а полная совокупность необходимых условий образует достаточные условия. С устранением из этой совокупности по крайней мере одного элемента условия перестают быть достаточными» (Никитин, 1970: 286). Как отмечает Ю. А. Зубок, «в социальном плане такую ситуацию, при которой нарушен баланс необходимых и достаточных условий, можно характеризовать как неопределенную. То есть многообразие возможностей, заложенных в необходимых условиях, превращается в действительность, но они не становятся достаточными условиями» (Зубок, 2007: 126).

Это наглядно прослеживается в трансформирующемся украинском обществе. Такая форма неструктурированности в постсоветском пространстве Украины проявилась в непродуманных реформах, когда поставленные цели (необходимые условия) не получили адекватного отражения в социальных и организационных структурах (достаточные условия). Примером может служить состояние неопределенности в реформируемой политической системе, в которой идеология «незалэжности» обернулась ростом радикального национализма, а стремление к демократизации - злоупотреблением властью в ее высших эшелонах, коррупцией, несоответствием узкопартийных целей реальным интересам общества.

Вторая форма - социально-ситуационная, в которой неструктурированность проявляется преимущественно на индивидуально-личностном уровне в процессе рефлексии повседневного опыта. Она выражается в неадекватном его отражении в ценностных, мотивационных, нормативных структурах, в доминировании спонтанно возникающих моделей поведения.

Взаимодействуя друг с другом, люди приобретают определенный опыт и знания, рефлектируя их как отношение к социальной реальности. В соответствии с определением Э. Гидденса под рефлективностью понимается способность социальных субъектов осознавать и поддерживать постоянное «теоретическое понимание оснований (причин) своей деятельности» (Гидденс, 1995: 41-42), т. е. адекватно реагировать на изменение внешних условий и на взаимное влияние друг на друга. Проявление этой способности в системе социальных отношений называется социальной рефлексией.

В условиях неопределенности возможности адекватной реакции субъектов социальной реальности на ее изменение существенно ограничиваются. Это происходит, с одной стороны, в связи с недостатком надежной информации о процессах, происходящих в обществе, которая в условиях деформации социальных институтов вытесняется разного рода слухами и мифами, а с другой - со снижением способности 
к саморефлексии социальных субъектов. Рефлектировать - означает «не просто знать, а знать, что знаешь» (Тейяр де Шарден, 1987: 136). На практике это проявляется в уверенности в надежности приобретаемых знаний, в адекватном понимании признаков существующей реальности. Неопределенность же снижает эту уверенность, что и отражается на способности к рефлексии. Отсюда социально-ситуационная неструктурированность, проявляющаяся в неадекватном отражении социальных изменений в ценностных, мотивационных, нормативных структурах личности. Это приводит к девальвации ценностей, к мифологизации и парадоксальности сознания, к утрате нравственных критериев в выборе моделей социального поведения.

На основе результатов социологического исследования, которое было проведено в 26 областях Украины в 2012 г. Институтом социологии Национальной академии наук Украины под руководством академика В. М. Вороны (выборка 1800 чел.), проанализируем проявление неопределенности в изменяющейся социальной реальности в трансформирующемся украинском обществе.

О появлении нового типа социальной реальности в этот период можно судить по распределению ответов на вопрос: «Как вы оцениваете характер изменений, происшедших в вашей жизни за последние 12 месяцев?» (табл. 1).

Как следует из анализа показателей табл. 1, отмечается негативная тенденция изменения всех без исключения характеристик социальной реальности. Значения оценок их ухудшения заметно (в разы) превосходят значения оценок улучшения этих характеристик. Наибольший разрыв отмечается в соотношении оценок гарантии занятости (ухудшение - 48\% против улучшения - 2,9\%; K= 2,32); материальных условий семьи $(48,1 \%$ против $6,8 \% ; \mathrm{K}=2,40)$; социальной защищенности $(43,6 \%$ против $2,6 \% ; \mathrm{K}=2,41)$. В данной тенденции отразился результат рефлексии респондентов на изменение объективной реальности. Аеформация структур занятости, тенденция ухудшения материальных условий жизни, снижения уровня социальной защищенности и других характеристик свидетельствуют об изменении социальной реальности в украинском обществе. Новая реальность, характеризующаяся размыванием привычных структур, отражается в общественном и индивидуальном сознании как состояние неопределенности.

Об этом свидетельствуют ответы на вопрос: «Согласны ли вы со следующими суждениями?» (табл. 2, с. 76).

Анализ показателей, представленных в табл. 2, позволяет сделать следующие выводы. Во-первых, в сознании большинства респондентов доминирует представление об украинском обществе как быстро меняющемся $(76,1 \%)$, неустойчивом $(80,7 \%)$, беспорядочном $(76,1 \%)$. С этим связывается состояние неопределенности, проявляющейся в ожидании непредвиденных последствий («может произойти все что угодно) $80,7 \%$; в девальвации базовых ценностей («трудно понять, во что верить» - 76,1\%, «большинство вообще ни во что не верит» - 80,5\%); в деформации общественных норм ( «не поймешь, каким законам следовать»- 76,1\%; «раньше каждый знал, как поступать правильно» - 68,8\%). Во-вторых, внутренняя дезорганизация и социальная неопределенность в украинском обществе проявились в разрушении моральнонравственных устоев («большинство людей способно солгать, чтобы продвинуться по службе» - 78,3\%; «готовы пойти на нечестный поступок ради выгоды» - 70,6\%). В-третьих, невозможность адекватной рефлексии социальных субъектов в условиях неопределенности привела к распространению недоверия в обществе ( нникому не доверять - самое безопасное» - 57\%). 
ИЗМЕНЕНИЕ СОЦИААЬНОЙ РЕААЬНОСТИ

Таблича 1

Table 1

CHANGES IN SOCIAL REALITY

\begin{tabular}{|c|c|c|c|c|c|c|c|}
\hline \multirow[b]{2}{*}{$\begin{array}{c}\text { Характеристики } \\
\text { сочииальной реальности }\end{array}$} & \multicolumn{5}{|c|}{$\begin{array}{c}\text { Оиенка характера изменений, } \\
\text { в \% к ответившим }\end{array}$} & \multirow{2}{*}{ 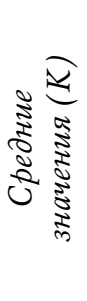 } & \multirow[b]{2}{*}{$\underset{\Sigma}{\tilde{Z}}$} \\
\hline & 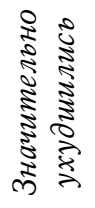 & 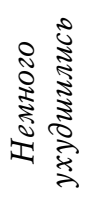 & 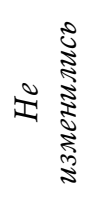 & 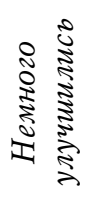 & 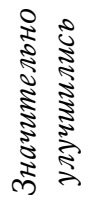 & & \\
\hline Материальные условия семьи & 18,5 & 29,6 & 45,1 & 6,2 & 0,6 & 2,40 & 11 \\
\hline Медицинское обслуживание & 18,0 & 23,0 & 55,7 & 2,9 & 0,4 & 2,54 & 9 \\
\hline $\begin{array}{l}\text { Гарантии занятости, обеспече- } \\
\text { ние работой }\end{array}$ & 23,7 & 24,3 & 49,1 & 2,4 & 0,5 & 2,32 & 12 \\
\hline $\begin{array}{l}\text { Условия отдыха во время } \\
\text { отпуска }\end{array}$ & 12,3 & 20,1 & 63,2 & 3,8 & 0,6 & 2,60 & 6 \\
\hline $\begin{array}{l}\text { Условия отдыха и досуга после } \\
\text { работы }\end{array}$ & 8,8 & 17,7 & 68,7 & 4,1 & 0,7 & 2,70 & 5 \\
\hline Аоступность информации & 6,6 & 17,7 & 64,7 & 9,5 & 1,5 & 2,81 & 2 \\
\hline Условия воспитания детей & 6,4 & 13,8 & 71,6 & 6,9 & 1,3 & 2,83 & 1 \\
\hline $\begin{array}{l}\text { Возможность высказывать } \\
\text { собственные взгляды }\end{array}$ & 6,8 & 17,3 & 69,3 & 5,6 & 1,0 & 2,76 & 3 \\
\hline $\begin{array}{c}\text { Возможность участвовать } \\
\text { в культурной жизни }\end{array}$ & 8,1 & 15,3 & 70,5 & 5,1 & 1,0 & 2,75 & 4 \\
\hline Состояние окружающей среды & 12,4 & 25,3 & 59,6 & 2,1 & 0,6 & 2,53 & 8 \\
\hline Социальная защищенность & 18,0 & 25,6 & 53,8 & 2,4 & 0,2 & 2,41 & 10 \\
\hline Аичная безопасность & 12,7 & 23,2 & 61,5 & 2,3 & 0,3 & 2,54 & 7 \\
\hline
\end{tabular}

Примечание: $\mathrm{K}$ - средневзвешенный коэффициент по пятибалльной шкале оценок.

По мнению Э. Гидденса, взаимное доверие, понимаемое как стремление положиться (минимизировать опасность) на партнера взаимодействий в пределах допустимого или приемлемого (калькулируемого) риска, является ключевым элементом рефлексивной формы взаимодействий (Гидденс, 1995: 41-42). При этом социолог выделяет два вида доверия. Аоверие системе - способности органов управления снизить потенциальные риски и доверие индивидам - убежденности в их надежности, т. е. в преемственности их самоидентификации. Аля этого необходимо быть уверенным в адекватности собственных знаний о партнерах, будь то личность или организация, т. е. понимать их истинные намерения. Состояние уверенности результируется в доверии или недоверии партнерам, отражая максимально достигнутую степень определенности в социальных взаимодействиях. Поэтому уровень доверия/недоверия можно рассматривать в качестве показателей социальной определенности/неопределенности (табл. 3, с. 77). 
ОТРАЖЕНИЕ НЕОПРЕАЕАЕННОСТИ В СОЗНАНИИ РЕСПОНАЕНТОВ

Таблиия 2

Table 2

REFLECTION OF UNCERTAINTY IN MASS CONSCIOUSNESS

\begin{tabular}{|c|c|c|c|}
\hline \multirow{2}{*}{ Суждения } & \multicolumn{3}{|c|}{$\begin{array}{c}\text { Распределение ответов, } \\
\text { в \% к ответившим }\end{array}$} \\
\hline & Согласен & Не согласен & Не знаю \\
\hline $\begin{array}{l}\text { Сейчас все так неустойчиво, что может произойти } \\
\text { все что угодно }\end{array}$ & 80,7 & 10,2 & 9,1 \\
\hline $\begin{array}{l}\text { При нынешнем беспорядке и неясности трудно } \\
\text { понять, во что верить }\end{array}$ & 76,1 & 15,8 & 8,1 \\
\hline $\begin{array}{l}\text { Все так быстро теперь меняется, что не поймешь, } \\
\text { каким законам следовать }\end{array}$ & 76,1 & 13,9 & 10,0 \\
\hline $\begin{array}{l}\text { Многое из того, во что верили наши отцы, } \\
\text { разрушается на глазах }\end{array}$ & 85,2 & 6,8 & 8,0 \\
\hline $\begin{array}{l}\text { Проблема сейчас в том, что большинство людей } \\
\text { вообще ни во что не верит }\end{array}$ & 80,5 & 11,0 & 8,5 \\
\hline $\begin{array}{l}\text { Раньше люди лучше себя чувствовали, потому что } \\
\text { каждый знал, как поступать правильно }\end{array}$ & 68,8 & 18,0 & 13,2 \\
\hline $\begin{array}{l}\text { Я считаю, что большинство людей способно солгать, } \\
\text { чтобы продвинуться по службе }\end{array}$ & 78,3 & 11,1 & 10,6 \\
\hline $\begin{array}{l}\text { Я думаю, что большинство людей готовы пойти } \\
\text { на нечестный поступок ради выгоды }\end{array}$ & 70,6 & 15,7 & 13,7 \\
\hline Никому не доверять - самое безопасное & 57,0 & 29,0 & 14,0 \\
\hline
\end{tabular}

Анализ данных, представленных в табл. 3, показывает, что уровень доверия в украинском обществе определяется степенью близости (родственной, деловой и духовной) в социальных взаимодействиях. Наиболее высокий его уровень отмечается по отношению к членам семьи (суммарное значение оценок «скорее доверяю》 и «полностью доверяю» составило 94,4\%); к коллегам по работе (49,5\%); к представителям духовенства (48\%); к соотечественникам (43\%); к соседям (49,2\%). Причем соотношение оценок доверия и недоверия здесь склоняется в пользу доверия, что нашло отражение в высоких значениях средневзвешенных коэффициентов, значительно превышающих три балла по пятибалльной шкале оценок. То есть доверие возрастает, если персонифицируется, приобретая в процессе идентификации с партнером взаимодействий личностную форму - прямой заинтересованности либо духовной близости. Поэтому украинские граждане склонны больше доверять индивидам, по Гидденсу, видя в их надежности залог определенности.

В меньшей степени проявляется доверие системе, т. е. общественным институтам. Недоверие в оценках отношения к ним преобладает над значениями оценок доверия. СМИ доверяют 29,9\% респондентов, а не доверяют $-34,6 \%(\mathrm{~K}=2,89)$; армии соответственно - 26,7\% против $33,6 \%(\mathrm{~K}=2,83)$; профсоюзам - 14,9\% против $47,4 \%(\mathrm{~K}=2,50)$; руководителям государственных предприятий $-11,8 \%$ против $48 \%$ $(\mathrm{K}=2,46)$; местным органам власти $-15,5 \%$ против $56,1 \%(\mathrm{~K}=2,35)$. Отрицательные 
УРОВЕНЬ АОВЕРИЯ В УКРАИНСКОМ ОБЩЕСТВЕ, 2012 Г.

Таблища 3

Table 3

LEVEL OF TRUST IN THE UKRAINIAN SOCIETY, 2012

\begin{tabular}{|c|c|c|c|c|c|c|c|}
\hline \multirow{2}{*}{$\begin{array}{c}\text { Аичности, } \\
\text { институть, } \\
\text { организачии }\end{array}$} & \multicolumn{5}{|c|}{$\begin{array}{c}\text { Оченка уровня доверия, } \\
\text { в \% к ответившим }\end{array}$} & \multirow{2}{*}{ 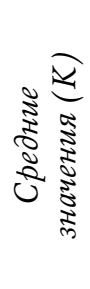 } & \multirow[b]{2}{*}{$\underset{\Sigma}{\tilde{z}}$} \\
\hline & 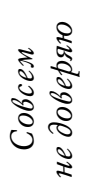 & 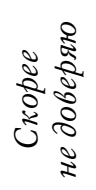 & 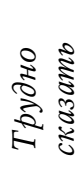 & 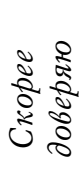 & 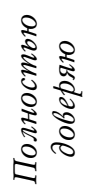 & & \\
\hline Членам семьи & 0,7 & 1,7 & 3,1 & 34,1 & 60,3 & 4,52 & 1 \\
\hline Соотечественникам & 3,6 & 12,2 & 41,2 & 35,6 & 7,4 & 3,31 & 4 \\
\hline Соседям & 5,1 & 16,9 & 28,8 & 42,6 & 6,6 & 3,29 & 5 \\
\hline Коллегам по работе & 3,4 & 10,4 & 36,6 & 43,6 & 5,9 & 3,38 & 2 \\
\hline Церкви и духовенству & 9,4 & 12,5 & 26,2 & 34,4 & 13,6 & 3,34 & 3 \\
\hline СМИ & 8,6 & 26,0 & 35,4 & 27,6 & 2,3 & 2,89 & 6 \\
\hline Милиции & 30,9 & 35,6 & 24,7 & 8,0 & 0,8 & 2,12 & 14 \\
\hline Прокуратуре & 30,0 & 34,9 & 27,2 & 7,2 & 0,8 & 2,14 & 13 \\
\hline Судам & 31,8 & 34,6 & 24,9 & 7,5 & 1,1 & 2,11 & 15 \\
\hline Президенту & 31,8 & 29,9 & 22,5 & 13,2 & 2,6 & 2,25 & 11 \\
\hline Верховной Раде & 35,7 & 35,5 & 21,4 & 6,6 & 0,7 & 2,01 & 18 \\
\hline Правительству & 33,9 & 33,8 & 22,5 & 8,6 & 1,3 & 2,09 & 16 \\
\hline Местным органам власти & 24,8 & 31,3 & 28,3 & 14,5 & 1,0 & 2,35 & 10 \\
\hline Армии & 13,3 & 20,3 & 39,7 & 23,3 & 3,4 & 2,83 & 7 \\
\hline Профсоюзам & 19,4 & 28,0 & 37,8 & 12,9 & 2,0 & 2,50 & 8 \\
\hline Политическим партиям & 32,9 & 37,1 & 24,3 & 5,1 & 0,7 & 2,03 & 17 \\
\hline $\begin{array}{l}\text { Руководителям } \\
\text { гос. предприятий }\end{array}$ & 18,1 & 29,9 & 40,3 & 11,0 & 0,8 & 2,46 & 9 \\
\hline Банкам & 30,3 & 31,5 & 29,3 & 12,2 & 0,7 & 2,22 & 12 \\
\hline
\end{tabular}

Примечание: К - средневзвешенный коэффициент по пятибалльной шкале оценок.

значения в соотношении доверия и недоверия институтам являются отражением дисфункции институциональных механизмов социальной регуляции, свидетельствующей о состоянии неопределенности в обществе.

Еще в более высокой степени проявилось недоверие к политическим институтам. Президенту в этот период доверяли $15,8 \%$, а не доверяли 61,7\% (K=2,25); Правительству - 9,9\% против 67,7\% $(\mathrm{K}=2,09)$; Верховной Раде - 7,3\% против $71,2 \%(\mathrm{~K}=2,01)$; политическим партиям - 5,8\% против $70 \%(\mathrm{~K}=2,03)$. В недоверии к власти отразилась неуверенность большинства людей в способности существующей политической системы снизить потенциальные риски, возникающие во всех сферах общественной 
жизни. Неспособной повысить уровень определенности в обществе оказалась в представлении людей и правоохранительная система, уровень доверия к которой не превышает $9 \%$. Причем не доверяют прокуратуре $64,9 \%$, милиции - 66,5\%, судам $66,4 \%$. В условиях, когда две трети населения не доверяют власти и правоохранительным органам, неопределенность приобретает системный характер и становится доминирующей характеристикой социальных взаимодействий в обществе.

Исследования, проведенные в разные годы Институтом социологии НАН Украины под руководством академика В. М. Вороны, позволяют выявить динамику изменения данного процесса (табл. 4).

ИЗМЕНЕНИЕ УРОВНЯ АОВЕРИЯ ПОАИТИЧЕСКИМ ИНСТИТУТАМ

И ПРАВООХРАНИТЕАЬНЫМ ОРГАНАМ В ПЕРИОА С 2005 ПО 2012 Г.

Таблица 4

Table 4

THE CHANGES IN THE LEVEL OF TRUST IN POLITICAL INSTITUTIONS

AND LAW ENFORCEMENT AGENCIES OVER THE PERIOD FROM 2005 TO 2012

\begin{tabular}{|l|c|c|c|c|c|}
\hline \multirow{2}{*}{\multicolumn{1}{|c|}{ Институтьл }} & \multicolumn{5}{|c|}{ Уровень доверия (K) } \\
\cline { 2 - 6 } & 2005 & 2007 & 2009 & 2011 & 2012 \\
\hline Правительству & 4,25 & 2,17 & 1,53 & 2,25 & 2,09 \\
Верховной Раде & 4,80 & 2,32 & 1,66 & 1,99 & 2,01 \\
Политическим партиям & 3,61 & 2,31 & 1,66 & 1,99 & 2,03 \\
Судебно-правовой системе & 3,91 & 2,45 & 1,91 & 2,26 & 2,11 \\
Милиции & 3,30 & 2,61 & 2,27 & 2,50 & 2,12 \\
Средние значения & 3,97 & 2,37 & 1,81 & 2,20 & 2,07 \\
\hline
\end{tabular}

Примечание: К - средневзвешенный коэффициент по пятибалльной шкале оценок.

Из анализа данных, представленных в табл. 4, следует, что в период с 2005 по 2009 г. происходило снижение уровня доверия ко всем политическим институтам и правоохранительным органам. Средние значения средневзвешенных коэффициентов снизились с 3,97 в 2005 г. - до 1,81 в 2009 г. $\Lambda$ ишь в 2011 г. отмечается некоторое повышение значений доверия до 2,2 балла, но уже на следующий год вновь произошло их снижение $(2,07)$. То есть прослеживается последовательная тенденция снижения уровня доверия в обществе, свидетельствующая о росте социальной неопределенности.

Системный характер данной тенденции подтверждается и распределением по годам ответов респондентов на вопрос: «Как вы считаете, в целом большинству людей можно доверять или стоит быть осторожным, имея дело с людьми?» Средневзвешенные значения ответов распределились следующим образом. В 2005 г. $\mathrm{K}=4,45$, в 2007 г. $-4,14$, в 2009 г. $-4,11$, в 2011 г. $-4,22$. 


\section{УРОВЕНЬ АОВЕРИЯИ СОЦИААЬНАЯ ОПРЕАЕАЕННОСТЬ В СТРАНАХ ЕВРОПЫ}

Возникает вопрос: является ди состояние неопределенности специфически украинским явлением или оно отражает общую тенденцию развития современных обществ? Сравним уровень доверия к государственно-политическим институтам в странах Европы, используя результаты «Европейского социального исследования» (Головаха, Горбачик, 2012: 115) (табл. 5, с. 80).

Как видно по табл. 5, в Украине самое низкое среднее суммарное значение доверия $(2,12)$ по сравнению со всеми другими странами Европы. Иишь доверие политикам $(1,85)$ и политическим партиям $(1,99)$ превосходит аналогичные оценки в Греции $(1,35$ и 1,37$)$ и в Хорватии $(1,61$ и 1,75$)$. Наиболее высокий разрыв средних суммарных значений оценок отмечается в Украине по сравнению со странами северной Европы с Аанией $(6,21)$, с Норвегией $(5,99)$, Швецией $(5,99)$, Финляндией $(5,86)$. Вместе с тем даже в этих небольших и весьма благополучных странах уровень доверия составляет в среднем около 6 баллов $(6,01)$. Это свидетельствует о том, что социальная неопределенность хотя и в меньшем масштабе, но все же проявляется и в этих странах, особенно в отношении к политикам и политическим партиям.

Более чем в два раза по суммарным средним значениям доверия Украина отстает от крупных индустриально развитых стран Европы - от Германии (2,12 и 4,72), Великобритании $(2,12$ и 4,51) и Франции $(2,12$ и 4,21). Однако изменения, характерные для эпохи постмодернизма, связанные с глобализацией и ускорением во всех сферах жизнедеятельности, проявились и в этих странах в снижении предсказуемости и постоянства жизненных ситуаций, т. е. в неопределенности. Относительно высокие значения доверия судебно-правовой системе и правоохранительным органам, превышающие 5 баллов, уступают оценкам доверия политическим институтам - парламенту $(4,31-$ в Германии, 4,11 - в Великобритании, 4,15 - во Франции), политическим партиям (соответственно - 3,36, 3,52 и 3,09). В среднем уровень доверия в этих странах составляет 4,48 балла.

Разрыв в уровне доверия в Украине заметно сокращается, хотя и остается достаточно высоким по сравнению с традиционно менее развитыми странами юга Европы, переживающими в настоящий момент острый кризис. В среднем уровень доверия в этих странах составляет 3,38 балла против 2,12 в Украине. По сравнению с Испанией разрыв составил 4,08 к 2,12 в Украине; с Португалией, соответственно - 3,13 к 2,12; с Грецией $-2,64$ к 2,12. То есть в снижении уровня доверия и в росте социальной неопределенности во многом проявляется влияние уровня экономического развития и кризисных явлений.

Среди стран бывшего социалистического лагеря Украина также находится на последнем месте по уровню доверия. Однако в этих странах этот показатель различается довольно существенно. В Венгрии, Чешской Республике и Эстонии он выше и составляет в среднем более 4 баллов $(4,04)$ и превосходит уровень доверия и социальной определенности в странах юга Европы (3,38 балла). А в Польше, Российской Федерации, Словакии и Болгарии он в среднем ниже (3,24 балла). То есть социокультурный фактор (принадлежность к славянской культуре) оказывает более сильное влияние на доверие и состояние социальной определенности/неопределенности в обществе, чем социально-политический.

Об устойчивости состояния неопределенности в украинском обществе позволяют судить ответы на вопрос: «Как вы считаете, в ближайший год наша жизнь более или 
АОВЕРИЕ ГРАЖААН ЕВРОПЕЙСКИХ СТРАН К ГОСУААРСТВЕННО-ПОАИТИЧЕСКИМ

Таблица 5

ИНСТИТУТАМ В 2011 Г. (СРЕАНИЙ БАА ПО ШКААЕ:

$0-$ «СОВСМ НЕ АОВЕРЯЮ», $10-$ «ПАНОСТЬЮ АОВЕРЯЮ»)

Table 5

LEVEL OF TRUST IN THE STATE AND POLITICAL INSTITUTIONS IN EUROPEAN SOCIETIES, 2011

(AVERAGE SCORE ON A SCALE FROM 0 - "NO TRUST" TO 10 - “COMPLETE TRUST")

\begin{tabular}{|c|c|c|c|c|c|c|}
\hline & 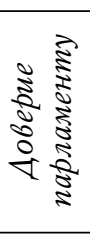 & 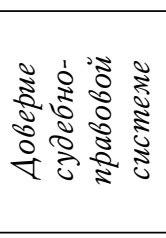 & 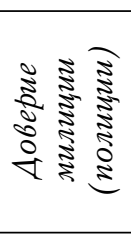 & 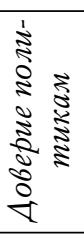 & 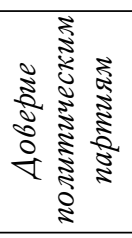 & 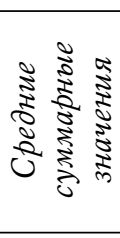 \\
\hline Бельгия & 4,46 & 4,93 & 6,01 & 3,86 & 3,85 & 4,62 \\
\hline Болгария & 2,39 & 2,54 & 3,85 & 1,99 & 1,99 & 2,55 \\
\hline Швейцария & 5,80 & 6,28 & 7,03 & 5,01 & 4,81 & 5,79 \\
\hline Кипр & 4,56 & 5,58 & 5,46 & 3,55 & 3,48 & 4,53 \\
\hline $\begin{array}{l}\text { Чешская } \\
\text { Республика }\end{array}$ & 3,28 & 4,14 & 4,91 & 2,62 & 2,69 & 3,53 \\
\hline Германия & 4,31 & 5,68 & 6,86 & 3,37 & 3,36 & 4,72 \\
\hline Аания & 5,83 & 7,35 & 7,68 & 5,04 & 5,17 & 6,21 \\
\hline Эстония & 4,24 & 5,22 & 6,17 & 3,62 & 3,43 & 4,54 \\
\hline Испания & 4,29 & 4,41 & 6,25 & 2,74 & 2,71 & 4,08 \\
\hline Финляндия & 5,38 & 6,91 & 8,03 & 4,43 & 4,54 & 5,86 \\
\hline Франция & 4,15 & 4,94 & 5,64 & 3,21 & 3,09 & 4,21 \\
\hline Великобритания & 4,11 & 5,24 & 6,24 & 3,43 & 3,52 & 4,51 \\
\hline Греция & 2,04 & 3,83 & 4,63 & 1,35 & 1,37 & 2,64 \\
\hline Хорватия & 2,27 & 3,23 & 4,40 & 1,61 & 1,75 & 2,65 \\
\hline Венгрия & 4,22 & 4,64 & 5,10 & 3,20 & 3,15 & 4,06 \\
\hline Ирландия & 3,68 & 5,10 & 6,51 & 3,11 & 3,07 & 4,29 \\
\hline Израиль & 3,67 & 5,33 & 4,80 & 2,95 & 2,97 & 3,94 \\
\hline Голландия & 5,37 & 5,89 & 6,26 & 5,25 & 5,26 & 5,61 \\
\hline Норвегия & 6,02 & 6,85 & 7,20 & 4,94 & 4,93 & 5,99 \\
\hline Польша & 3,44 & 4,26 & 5,39 & 2,66 & 2,55 & 3,66 \\
\hline Португалия & 2,88 & 3,70 & 5,10 & 1,97 & 2,01 & 3,13 \\
\hline $\begin{array}{c}\text { Российская } \\
\text { Федерация }\end{array}$ & 3,57 & 3,84 & 3,53 & 3,04 & 3,05 & 3,41 \\
\hline Швеция & 6,28 & 6,53 & 6,98 & 5,04 & 5,11 & 5,99 \\
\hline Словения & 2,98 & 3,08 & 4,99 & 2,25 & 2,24 & 3,11 \\
\hline Словакия & 3,20 & 3,52 & 4,49 & 2,78 & 2,71 & 3,34 \\
\hline Украина & 1,99 & 2,26 & 2,50 & 1,85 & 1,99 & 2,12 \\
\hline
\end{tabular}


менее наладится или никакого улучшения не произойдет?» Ответы распределились следующим образом: никакого улучшения не будет - 51,4\%; трудно сказать - 33,7\%; более или менее наладится - 14,9\%. Аишь 14,9\% респондентов выразили неуверенную надежду на улучшение жизни, подтвердив тем самым, что состояние неопределенности в новой социальной реальности приобрело устойчивую форму.

\title{
ЗАКАЮЧЕНИЕ
}

Таким образом, проделанный анализ позволяет сделать следующие выводы. Вопервых, на примере Украины можно отметить многообразие форм проявления неопределенности в трансформирующемся обществе. Неопределенность проявляется как особый тип социальной реальности, характеризующийся деформацией структур занятости, тенденцией ухудшения материальных условий жизни, снижением уровня социальной защищенности и других характеристик; как состояние, в котором находится общество, социальная группа, личность, проявившееся в их внутренней дезорганизации, в разрушении морально-нравственных устоев; как невозможность адекватной рефлексии социальными субъектами усиливающейся нестабильности в обществе. Во-вторых, снижение уровня доверия в украинском обществе как показателя неопределенности в целом отражает общемировую тенденцию, связанную с процессом глобализации. В-третьих, тот факт, что Украина занимает последнее место по уровню доверия, свидетельствует о влиянии не только общих факторов (глобализации, кризиса, уровня экономического развития, политической стабильности), но и специфических условий историко-культурного развития страны.

\section{СПИСОК АИТЕРАТУРЫ}

Гидденс, Э. (1995) Элементы теории структурации // Современная социальная теория: Бурдье, Гидденс, Хабермас : учеб. пособие / под ред. А. В. Аеденевой. Новосибирск : Изд-во Новосибирск. ун-та. 119 с. С. 40-80.

Зубок, Ю. А. (2007) Феномен риска в социологии: опыт исследования молодежи. М. : Мысль. $288 \mathrm{c.}$

Никитин, Е. (1970) Условия // Философская энциклопедия : в 5 т. / под ред. Ф. В. Константинова. М. : Советская энциклопедия. Т. 5.740 с. С. 286-287.

Тейяр де Шарден, П. (1987) Феномен человека. М. : Наука. 240 с.

Головаха, Є., Горбачик, А. (2012) Тенденції соціальних змін в Україні та Європі: за результатами «Європейського соціального дослідження» 2005-2007-2009-2011. К. : Інститут соціології НАН України. 119 с. (На укр. яз.).

Аата поступления: 2.02.2015 г.

\author{
UKRAINIAN SOCIETY: THE CRISIS OF TRUST \\ IN THE SITUATION OF UNCERTAINTY \\ V. I. CHUPROV \\ (INSTITUTE OF SOCIO-POLITICAL RESEARCH, RAS), \\ V. V. MIKHEYEVA \\ (Moscow State University of Social SCIENCES ANd ECONomics)
}

The article deals with the problem of uncertainty in social interaction and its various forms in the transforming Ukrainian society. We pay special attention to the unstructured status of this society, to setting up a new type of social reality and its negative character, to versions of trust, levels of trust and mistrust in individuals and organizations. 
We make use of the outcomes of social survey held in 26 oblasts of the country in 2012 by the Institute of Sociology, National Academy of Science of Ukraine by the team led by V. M. Vorona, FNAS (a sample of 1800 respondents). The survey data revealed a negative trend in the change of all features of social reality. The majority of respondents see Ukrainian society as rapidly changing, unstable and chaotic. Levels of trust are determined by the degree of affinity (kinship, business relations or single-mindedness) in social interactions, accompanied by a fall in the level of trust in all political institutions and law enforcement agencies.

We conclude that Ukraine showcases a variety of forms of uncertainty manifestation in a transforming society, and that in Ukrainian society the level of trust is the lowest in Europe. This is due to both general factors (globalization, crisis, level of economic development, political stability) and those specific for Ukraine. Overall, the decrease of trust is typical for European societies.

Keywords: Ukraine, Ukrainian society, crisis in Ukraine, social interaction, trust, mistrust, social uncertainty, European social survey.

\section{REFERENCES}

Giddens, A. (1995) Elementy teorii strukturatsii [Elements of the theory of structuration]. In: Sovremennaia sotsial'naia teoriia: Burd'e, Giddens, Khabermas [Contemporary social theory: Bourdieu, Giddens, Habermas] : A textbook / ed. by A. V. Ledeneva. Novosibirsk, Novosibirsk University Publ. 119 p. Pp. 40-80. (In Russ.).

Zubok, Yu. A. (2007) Fenomen riska v sotsiologii: opyt issledovaniia molodezhi [The phenomenon of risk in sociology: A study of the youth]. Moscow, Mysl' Publ. 288 p. (In Russ.).

Nikitin, E. (1970) Usloviia [Conditions]. In: Filosofskaia entsiklopediia [The encyclopedia of philosophy] : in 5 vols. / ed. by F. V. Konstantinov. Moscow, Sovetskaia entsiklopediia Publ. Vol. 5. 740 p. Pp. 286-287. (In Russ.).

Teilhard de Chardin, P. (1987) Fenomen cbeloveka [The phenomenon of man]. Moscow, Nauka Publ. 240 p. (In Russ.).

Golovakha, E. and Gorbachik, A. (2012) Tendentsiï sotsial'nikb zmin v Ukrä̈ni ta Evropi: za rezul' tatami "Evropeis' kogo sotsial' nogo doslidzhennia» 2005-2007-2009-2011 [Trends of social change in Ukraine and Europe: The outcomes of "European Social Survey" 2005-2007-2009-2011]. Kyiv, Publ. House of the Institute of Sociology, National Academy of Science of Ukraine. 119 p. (In Ukr.).

Submission date: 2.02 .2015$.

Чупров Владимир Ильич - доктор социологических наук, профессор, заслуженный деятель науки РФ, главный научный сотрудник Института социально-политических исследований РАН. Адрес: 119333, Россия, г. Москва, ул. Фотиевой, А. 6, к. 1. Тел./факс: +7 (499) 530-28-84. Эл. алрес: osipov@ispr.ras.ru

Михеева Виталина Владимировна - кандидат исторических наук, доцент кафедры социологии Московского государственного социально-экономического университета. Адрес: 107150 , Россия, г. Москва, ул. Аосиноостровская, д. 49. Тел./ факс: +7 (499) 160-22-05. Эл. адрес: gonchar72@rambler.ru

Chuprov Vladimir Ilyich, Doctor of Sociology, Professor, Honored Worker of Science of the Russian Federation, Chief Research Fellow, Institute of Socio-Political Research, RAS. Postal address: 1 Bldg., 6 Fotieva St., 119333 Moscow, Russian Federation. Tel./fax: +7 (499) 530-28-84. E-mail: osipov@ispr.ras.ru

Mikheyeva Vitalina Vladimirovna, Candidate of History, Associate Professor, Department of Sociology, Moscow State University of Social Sciences and Economics. Postal address: 49 Losinoostrovskaya St., 107150 Moscow, Russian Federation. Tel./fax: +7 (499) 160-22-05. E-mail: gonchar72@rambler.ru 